\title{
Effect of prolonged therapy with neuroleptics on hepatic microsomal enzyme activity in schizophrenic patients
}

\author{
Sisir K. MAJUMdar \\ B.Sc., M.B. B.S.
}

\author{
Pravin P. Kakad \\ M.B. B.S., D.P.M.
}

Bexley Hospital, Bexley, Kent, DA5 2BW

\begin{abstract}
Summary
Gamma-glutamyl transpeptidase (GGT) is one of the hepatic microsomal enzymes and is now considered to be a reliable biochemical marker of enzyme induction.

Serum levels of this hepatic microsomal enzyme were estimated in twenty-eight schizophrenic patients treated with neuroleptics (fluphenazine, flupenthixol and chlorpromazine) for a prolonged period. No biochemical evidence of induction of the hepatic microsomal enzymes was noticed. It is suggested that these drugs may not cause hepatic microsomal enzyme induction in humans and that interference of rates of metabolism via enzyme induction in other drugs used concurrently need not be anticipated.
\end{abstract}

\section{Introduction}

The enzyme gamma-glutamyl transpeptidase (GGT) is widely distributed in the body, notably in the liver, kidney, brain, pancreas, seminal vesicles and the lactating breast.

In the liver it is present in the smooth surface of the endoplasmic reticulum of the hepatocyte where its activity is enhanced by situations leading to enzyme induction, for example, the induction by drugs such as phenytoin or phenobarbital (Goldberg and Martin, 1975; Leading Article, 1977). The effect is now reported of prolonged therapy with long- and short-acting neuroleptics (phenothiazines, thiozanthines, etc.) on gamma-glutamyl transpeptidase activity in schizophrenic patients.

\section{Patients, methods and results}

Twenty-eight patients, of whom seventeen were male and eleven female (age range 27-72 years; mean, $56 \cdot 86 \pm$ s.e. mean $2 \cdot 34$ years) were selected from one of the wards of Bexley Hospital, Kent. There was no evidence of any disease which might interfere with GGT activity, nor were the patients having drugs other than major tranquillizers.

Conventional liver function tests (Leading Article, 1977) were carried out and a relevant haematological profile obtained.
The mean serum level of GGT was $12.07 \pm 3.03$ s.e. mean. The group mean was not elevated and in only two of the individual cases was the level slightly higher than normal. Plasma proteins, serum bilirubin, alkaline phosphatase, aspartate transaminase and haematological profile $(\mathrm{Hb}, \mathrm{RBC}$, $\mathrm{WBC}$, platelets, $\mathrm{PCV}, \mathrm{MCV}, \mathrm{MCHC}, \mathrm{MCH}$ ) were all within normal limits.

\section{Treatment}

All patients were being treated with long-acting injectable tranquillizers (fluphenazine decanoate or flupenthixol decanoate). Duration of treatment ranged from 5 to 20 years. The dosage ranged in the case of flupenthixol from 30 to $160 \mathrm{mg} / \mathrm{month}$ and in the case of fluphenazine from 6.25 to $100 \mathrm{mg}$ / month. In addition, five of the patients were given oral chlorpromazine (250-450 mg daily).

\section{Discussion}

A knowledge of the presence of enzyme induction is of interest in a number of clinical situations. The technical ease of measurement of GGT and its reported sensitivity as an indicator of enzyme induction makes it a better choice as a biochemical marker than the other commonly used estimations D-glucaric acid and 6-pOH cortisol (Goldberg and Martin, 1975). GGT levels were therefore used as a marker in this study of the effect of long-acting neuroleptics on enzyme induction.

The patients under review are all chronic schizophrenics and have not suffered from the clinical conditions as recently reviewed which might interfere with serum GGT levels, nor have they had drugs, other than tranquillizers, known to interfere with microsomal enzymes (Goldberg and Martin, 1975; Leading Article, 1977).

Total serum bilirubin, alkaline phosphatase (ALP) aspartate transaminase (AST), gammaglutamyl transpeptidase (GGT), plasma proteins are all within normal limits except in two cases, where GGT was slightly higher. In both these cases 
the patients, in addition to long-acting injections, were taking chlorpromazine orally.

All of the drugs under consideration here are closely related to the phenothiazines in which two benzene rings are linked by a sulphur and a nitrogen atom. Chlorpromazine is a phenothiazine with an aliphatic side chain, fluphenazine is a phenothiazine with a piperazine group, and flupenthixol is a thioxanthene formed when nitrogen at position 10 of the phenothiazine ring is replaced by a carbon atom with a double bond to the side chain (Byck, 1975).

There are conflicting reports on the effect of chlorpromazine on hepatic microsomal enzymes in man. Lader (1976) reported a reduction in the halflife of antipyrine in five patients given $100 \mathrm{mg}$ of chlorpromazine 8-hourly for 3 weeks. In contrast, Stevenson et al. (1972), using the same antipyrine half-life technique, were unable to find any evidence of enzyme induction in ten schizophrenics given chlorpromazine in a dosage ranging from 150 to 600 $\mathrm{mg}$ daily for a minimum of 2 months. They found, however, that in isolated rat liver preparations, chlorpromazine was a weak enzyme inducer.

Latham, Padgham and Henryk-Gutt (1974), using urinary D-glucaric acid and plasma quinine halflives as indices of hepatic microsomal enzyme induction reported on six male patients treated with fluphenazine decanoate. These patients received 25 $\mathrm{mg}$ of fluphenazine decanoate monthly for a minimum period of one year. They found no evidence of enzyme induction.

The present findings support those of Stevenson et al. (1972) and those of Latham et al. (1974). Estimation of serum GGT in patients maintained for many years on fluphenazine decanoate, and $\frac{2}{2}$ flupenthixol decanoate (in some instances supple- $\stackrel{\mathbb{D}}{\triangle}$ mented by chlorpromazine), are within the normal. range.

It is therefore concluded that fluphenazine decanoate and flupenthixol decanoate do not induce hepatic microsomal enzymes in humans.

\section{Acknowledgments}

Grateful thanks are due to Dr G. K. Shaw, Consultant Psychiatrist, Bexley Hospital, Kent, for allowing us to study the patients under his care and for valuable guidance and suggestion in preparing this paper. We also thank the Chemical Pathology Department of Queen Mary's Hospital, Sidcup, Kent, for doing all necessary laboratory investigations in our patients.

\section{References}

BYCK, R. (1975) Drugs and the treatment of psychiatric disorders. In: The Pharmacological Basis of Therapeutics (Ed. Goodman, L.S. \& Gilman, A.), 5th edn, p. 152. Macmillan, New York.

GolDbERG, M.D. \& MARTIN, J.V. (1975) Role of $\gamma$-glutamyl ב transpeptidase activity in the diagnosis of hepatobiliary disease. Digestion. Basel, 12, 232.

LADER, M. (1976) Clinical psychopharmacology. In: Recent Advances in Clinical Psychiatry No. 2 (Ed. by Granviller Grossman, K.), p. 1. Churchill Livingstone, London Edinburgh.

latham, A.N., Padgham, C. \& Henryk-Gutt, R. (197 4 The effect of fluphenazine decanoate (Modecate) om. hepatic microsomal activity in man. British Journal \& Clinical Pharmacology, 1, 277.

LEADING ARTICle (1977) Are liver function tests outmoded? British Medical Journal, 2, 75.

Stevenson, I.H., O'Malley, K., Turnbull, M.J. \& BALLINGER, B.R. (1972) The effect of chlorpromazine on 을 drug metabolism. Journal of Pharmacy and Pharmacology, 24, 577. 